\title{
HUBUNGAN KEPRIBADIAN OTORITARIAN DENGAN PEMIDANAAN HAKIM
}

\author{
Yusti Probowati Rahayu \\ Universitas Surabaya
}

\begin{abstract}
Disparity of Sentences is delined as disparate sentencing toward the relative same criminal cases. The sentencing disparity lead to the rise unsatisf actory feeling. The purpose of this research was to know the effect of The authoritarian personality of The judges to the sentencing disparity.

90 subject of the research were 77 judges and 13 candidate of judges at the court of the first instance in DIYand Centre Java. They should make decision on the same criminal case, and filled the authoritarian scale. The data was analyzed with one way anova.

The result of this research showed that there was large sentencing disparity ( 0 to 126 months) although had been used a similar case. The Authoritarian personality of the judges had effect to the sentencing disparily. The judges with high authoritarian personality give severe sentence than the judges with midlle and low authoritarian personality. This research suggested to The Law Departement fo reduce the authoritarian personality of judges.
\end{abstract}

Key words: The sentencing of the judges, the authoritarian personality of judges, the disparity of sentencing.

\section{Pengantar}

Manusia selalu dlhadapkan pada pembuatan keputusan, balk dalam kehidupan sehari-hari maupun peran dalam masyarakat. Dalam kehidupan sehari-hari, manusia dihadapkan pada pengambilan keputusan berkaitan dengan masalah karier, rumah tangga, dan sekolah. Pada saat memainkan peran, baik sebagai dosen, manajer, psikolog, hakim, manusia harus mengambil keputusan terkait dengan orang lain. Misal, seorang dosen memutuskan mahasiswa dapat lulus atau tldak pada suatu matakuliah, seorang psikolog menentukan apakah calon karyawan layak diberi rekomendasi diterima atau ditolak pada posisi jabatan tertentu.

Peran hakim daiam proses peradilan tergolong penting, karena keputusan hakim akan memberlkan kekuatan hukum. Keputusan haklm pada perkara pidana akan menentukan apakah seorang terdakwa bersalah atau tldak. Jika bersalah, haklm akan menentukan apakah terdakwa dapat bertanggung jawab atau tidak sehingga hakim dapat menentukan seorang terdakwa dihukum atau tidak. Jika seorang terdakwa dihukum, hakim harus memutuskan berapa tahun pemldanaan yang layak diterima terdakwa sesuai perbuatan yang dllakukannya (Moeljatno, 1982; Rahayu, 1995).

Salah satu permasalahan dalam pemidanaan adalah disparitas pemidanaan. $\mathrm{Hal}$ ini pernah diangkat sebagai permasalahan dalam Musyawarah Nasional VIl Ikatan Hakim d Indonesia tahun 1975 , Musyawarah Nasional VIII Ikatan Hakim Indonesia di Jakarta tahun 1984, dan 
simposium terbatas pemidanaan oleh hakim Pengadilan Negeri dan Pengadian Tinggi Jakarta tahun 1992.

Disparitas pemidanaan diartikan sebagai penerapan pidana yang tidak sama terhadap tindak pidana yang sama atau terhadap tindak pidana yang sifatnya dapat diperbandingkan tanpa dasar pembenaran yang jelas (Cheang dalam Muladi dan Nawawi, 1992). Lebih jauh Poernomo (1994) menjeiaskan disparitas pemidanaan yang bermasalah adalah putusan hakim yang berbeda pada perkara yang relatif sama pada situasi dan kondiși yang sama.

Karnasudirdja (1983) mencontohkan disparitas yang seharusnya tidak terjadi dengan mengumpulkan pemidanaan dalam perkara tingkat grasi terhadap kejahatan pasal 359 KUHP (perkara lalu lintas yang menyebabkan korban meninggal) tahun 1977-1978. Digunakan 85 perkara dengan terdakwa sopir dan hasilnya dlketahui bahwa putusan hakim bervariasi (terjadi disparitas) antara enam bulan 15 harl hlngga 48 bulan, dengan rata-rata pemidanaan enam bulan tujuh hari. Contoh lain adalah kejahatan pasal 340 KUHP (pembunuhan berencana), diketahui pemidanaan hakim bervariasi (tejadi disparitas) antara enam bulan hingga 18 tahun, dengan rata-rata pemidanaan 7 tahun 7 bulan.

Disparitas pemidanaan mengakibatkan munculnya perasaan ketidakadilan, baik oleh terpidana maupun mas yarakat luas sehingga terpidana maupun masyarakat menjadi tidak menghargai hukum. Padahal penghargaan terhadap hukum merupakan salah satu target tujuan pemldanaan. Hal Inl juga merupakan salah satu indikatordan manifestasi dari kegagalan sistem guna mencapai keadilan di negara hukum dan sekaligus akan melemahkan kepercayaan masyarakat terhadap sistem penyelenggaraan hukum pidana.

Dalam kajian ps/kologi banyak faktor yang menyebabkan terjadinya disparitas pemidanaan hakim. Faktor hakim (jenis kelamin, ras, kepribadian otoritarian, status perkawinan), faktor terdakwa (jenis kelamin, ras, daya tarik), faktor saksi (daya tarik, jenis kelamin, ras, kepercayaan diri), faktor jaksa penuntut umum (kepribadian otoritarian, daya tarik), faktor pengacara (daya tarik, kemampuan berkomunikasi, ras), faktoropini publik sering dianggap sebagai faktor yang mempengaruhi terjadinya disparitas pemidanaan (Jones and Goethals, 1976; Gerasi, Zuckerman and Reis, 1977; Dane and Wrightsman, 1982; Baron and Byrne, 1982; Brigham, 1991; Zebrowitz and McDonald, 1991; Moran and comfort dalam Sabini 1992). Penelitian ini ingin mengetahui hubungan kepribadian otorilarian dengan disparitas pemidanaan hakim.

\section{Tinjauan Pustaka}

Altemeyer (1996) mendefinisikan individu berkepribadian otoritarian adalah indlvidu dengan kepatuhan yang tinggi terhadap otoritas, memiliki kepatuhan yang tinggi terhadap aturan sosial yang dlsosialisasikan oleh otoritas dan bersikap agreslf terhadap orang lain yang melanggar aturan yang dirasakan sebagai sanksi dari otoritas. Hakim yang berkepribadian otoritarian adalah hakim yang sangat patuh terhadap negara dan hukum, serta memberi hukuman berat sebagai penyaluran agresifitas atas nama hukum.

Dalam perkembangannya indivldu otorilarian selalu diberi tekanan akan adanya bahaya yang mengancam dl dunia inl. Oleh karena itu individu berkepribadian otoritarian sangat meyakini bahwa kejahatan merupakan bahaya bagi diri dan masyarakatnya. Selain itu, individu otoritarian yang patuh terhadap otoritas dan aturan seialu berpikir bahwa dirinya baik dan bajik, karena la selalu melihat dirinya stabil dalam memutuskan perilaku moralistik yang terkait dengan otoritas.

Perilaku kriminalitas yang melanggar aturan akan menimbulkan perasaan kecemasan terhadap ancaman. Hal ini akan menurunkan kestabllan dirl indivldu otoritarian. Oleh karena itu, untuk mengatasi kecemasan dan mempertahankan bahwa dirinya sebagal orang balk, maka individu otoritarian berperilaku kejam terhadap perilaku kriminal. Altemeyer (1996) menemukan ada korelasi antara kecemasan 
terhadap ancaman dunia dan perasaan bahwa dirinya orang bajik dengan agresi otoritarian.

Dalam memutuskan pemidanaan, hakim harus memikirkan segala aspek perilaku dan peristiwa kejahatan terdakwa agar tercapai suatu keadilan dan kebenaran yang memuaskan semua pihak. individu otoritarian belajar tentang kebenaran dari aturan-aturan orang tuanya. Sesuatu yang sesuai dengan aturan adalah benar dan yang tidak sesuai dengan aturan adalah salah. individu otoritarian tidak pernah belajar bahwa kebenaran harus dicari dan dipertimbangkan. Individu otoritarian tidak pemah belajar kritis. Hakim berkepribadian otoritarian tinggi akan memukuskan perkara sesuai dengan aturan tanpa mempertimbangkan secara mendalam segala aspek yang terkait dengan keadilan. Kriminalitas yang mengancam rasa aman dan kestabilannya sebagai orang bajk, akan menyebabkan hakim mengambil keputusan kriminalitas harus dihukum berat.

Kepribadian otoritarian merupakan sindrom kepatuhan yang berlebihan terhadap otoritas, norma, dan nilai-nilal. indivldu berkepribadian otoritarian melakukan agresi dengan dalih demi kebaikan bagi masyarakat. Billing, Guastello, dan Rieke (1993) memberikan karakteristik kepribadian otoritarian terkait dengan rendahnya imajinasi, pemikiran konkrit, tidak sensilif, pikiran tertutup, curiga dan serius. Hal ini menyebabkan hakim berkepribadian otoritarian mementingkan pertimbangan dirinya yang mengacu pada hukum menurut dirinya sendiri.

Rickman, Burns, dan Robbins (1986), Mitchel dan Byrne (Brigham, 1991), Moran dan Comfort (Sabini, 1992), Christie (Feather, 1996) menemukan bahwa juri dengan kepribadian otoritarian lebih sering berpikir bahwa terdakwa bersalah dan akhirnya memutuskan bersalah. Altemeyer (1996) mengatakan bahwa individu berkepribadian otoritarian tinggi cenderung memberikan hukuman berat pada para kriminal. Semua penelitian d atas dilakukan di negara barat dengan sistem hukum yang berbeda dengan di Indonesia. Oleh karena itu penelitian ini ingin mengetahul apakah kepribadian otoritarian hakim memberikan pengaruh terhadap berat ringannya pemidanaan hakim.

\section{Metode Penelitian}

\section{Subyek}

Penelitian ini menggunakan 77 subjek penelitian hakim dan 13 calon haklm dl Daerah Istimewa Yogyakarta (Pengadllan Negeri Yogyakarta, Sleman, Wonosarl dan Wates) dan Jawa Tengah (Pengadilan Negeri Magelang, Temanggung, Salatiga, Boyolali, Kłaten, Purworejo, Kebumen).

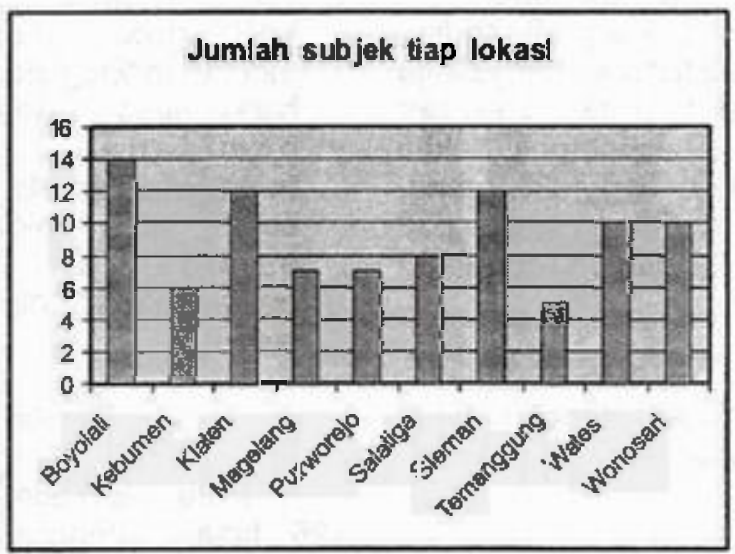

PSIKOLOGIKA Nomer 24 Tahun XII Jeli 2007 
Karakteristik subjek penelitian adalah hakim dan calon hakim Pengadilan Negeri dan lokasi Pengadilan Negeri di Daerah Istimewa Yogyakaria dan Jawa Tengah. Digunakannya calon hakim karena sulitnya mencari hakim yang bersedia sebagai subjek penelitian. Calon hakim diasumsikan telah masuk menjadi baglan dari hakim.

\section{Metode Pengumpulan Data}

Metode pengumpulan data pemidanaan dilakukan dengan memberi subjek penelitian perkara pidana dan subjek diminta memberikan pemidanaan sesuai dengan pertimbangannya masing-masing. Perkara pidana yang diberikan merupakan perkara riil yang dimodifikasi oleh peneliti dengan dibantu ahli dalam bidang hukum pidana. Perkara pldana yang diambil merupakan perkara blasa pada kasus pembunuhan (dakwaan pasal $338 \mathrm{KUHP}$, pasal 354 ayat2, pasal 351 ayat 3 ).

Skala kepribadian otoritarian disusun oleh peneliti dengan mengacu pada teori kepribadian otoritarian Altemeyer. Skala yang digunakan adalah summated rating dengan 7 pilihan. Skala diujicobakan pada 80 sarjana hukum dan berusia produktif. Pemilihan subjek uji coba disesuaikan dengan kriteria subjek penelitian. Dari 70 aitem diperoleh 38 aitem valid setelah dianalisis butir dengan menggunakan bantuan SPPS. Nilai kepribadian otoritarian hakim dibagi menjadi tiga kelompok berdasarkan pembagian menurut frekuensi jumlah relatif sama pada tiga kelompok. Metode pembagian tersebut seperti median yang membagi dua sama banyak, hanya saja digunakan pembaglan tiga. Dengan pembaglan ini diperoleh kelompok hakim berkepribadian otoritarian tinggi 28 orang, kelompok kepribadlan otorltarlan sedang 32 orang dan keprlbadlan otoritarian rendah 30 orang.

\section{Anallsis Data}

Analls ls data dilakukan dengan anava 1 jalan dan diolah dengan bantuan program komputer SPSS.

\section{Hasil Penelitian}

Sembilan puluh subjek penelitian memutuskan pemidanaan yang bervariasi pada perkara yang sama. Rentang pemidanaan subjek penelitian dari 0 (memutuskan lepas) hingga 126 bulan (10 tahun 6 bulan). Berdasarkan hasil anava 1 jalan diperoleh nilai $F=10,592$ dengan $p=$ 0.0001 . ini menunjukkan bahwa ada perbedaan pemidanaan antara kelompok haklm berkepribadian otoritarian tinggi, sedang, dan rendah. Lebih lanjut dilakukan uj scheffe dan diperoleh hasil sebagai berikut:

1. Ada perbedaan pemidanaan antara kelompok hakim berkepribadian otoritarlan rendah dengan kelompok haklm berkepribadian otoritarian sedang. Rerata pemidanaan hakim kelompok berkepribadian otoritarian sedang $(61,56$ bulan) lebih tinggl dibanding rerata pemidanaan kelompok hakim berkepribadian otoritarian rendah $(42,57$ bulan)

2. Ada perbedaan pemidanaan antara kelompok hakim berkepribadian otoritarian rendah dengan kelompok hakim berkepribadian otoritarian tinggi. Rerata pemidanaan hakim kelompok berkepribadian otoritarian tinggi $(86,39$ bulan) lebih tinggl dibanding rerata pemidanaan ketompok hakim berkepribadian otoritarian rendah $(42,57$ bulan)

3. Ada perbedaan pemidanaan antara kelompok hakim berkepribadian otoritarian tinggi dengan kelompok hakim berkepribadian otoritarian sedang. Rerata pemidanaan hakim kelompok berkepribadian otoritarian sedang $(61,56$ bulan) lebih rendah dibanding rerata pemidanaan kelompok hakim berkepribadian otoritarian tlnggi $(86,39$ bulan)

\section{Pembahasan}

Perbedaan pemidanaan darl $0 \mathrm{hingga}$ 126 bulan, menunjukkan bahwa terjadi disparitas pemidanaan yang besar antar 
subjek penelitian. Disparitas pemidanaan merupakan masalah besar dalam pengambilan keputusan hakim karena berdampak pada perasaan keadilan baik pada terpidana maupun masyarakat. Penelitian ini memberikan bukti bahwa masalah disparitas pemidanaan hakim terjadi bahkan pada perkara yang sama persis.

Hasil penelitian (baik hasil analisis data anava maupun dengan uj scheffe) menunjukkan adanya perbedaan pemidanaan antara kelompok hakim berkepribadian otoritarian tinggi, sedang, dan rendah. Ini berarti kepribadian otoritarian hakim memberikan pengaruh terhadap pemldanaan hakim. Hakim dengan kepribadian otoritarian tinggi memberikan pemidanaan yang lebih berat dibanding hakim dengan kepribadian otoritarian sedang dan rendah. Jadi kepribadian otoritarian hakim merupakan salah satu faktor penyebab terjadinya disparitas pemidanaan hakim.

Hasil penelitian ini sesuai dengan hasil penelitian Rickman, Burns, dan Robbins (1986), Mitchel dan Byrne (Brigham, 1991), Moran dan Comfort (Sabini, 1992), Christie (Feather, 1996) yang menemukan bahwa juri dengan kepribadian otoritarian lebih sering berpikir bahwa terdakwa bersalah dan memutuskan bersalah. Altemeyer (1996) mengatakan bahwa individu berkepribadian otoritarian tinggi cenderung memberikan hukuman berat pada para kriminal.

individu berkepribadian otoritarian tinggi merupakan individu yang patuh terhadap otoritas dan aturan. Individu selalu berpikir bahwa dirinya baik dan bajik karena ia melihat dirinya stabil dalam memutuskan perilaku moralistik. Perilaku kriminal yang melanggar aturan dirasakan sebagai ancaman, baik bagi dirinya maupun masyarakat. Hal ini menimbulkan kecemasan dalam dirinya yang mengaklbatkan individu berkepribadian otoritarian tinggi akan memberikan hukuman berat terhadap pelaku kriminal, sebagai usaha mengurangi kecemasannya.

Hasil ini dapat digunakan sebagai masukan bagi Departemen Hukum dan
Perundang-undangan Republik Indonesia agar mengurangi bias akibat kepribadian otoritarian. Salah satu cara mengurangi bias tersebut dengan memberikan pelatihan yang bertujuan mengurangi tingginya kepribadian otoritarian hakim. Altemeyer (1996) menyatakan bahwa kepribadian otoritarian dapat dikurangi dengan program-program pelatihan tertentu.

\section{Penutup}

Hasil penelitian menunjukkan ada perbedaan pemidanaan antara kelompok hakim berkepribadian otoritarian tinggi, sedang, dan rendah. Ada perbedaan pemidanaan antara kelompok hakim berkepribadian otoritarian rendah dengan kelompok hakim berkepribadian otoritarian sedang. Rerata pemidanaan hakim kelompok berkepribadlan otoritarian sedang (61,56 bulan) lebih tinggi dibanding rerata pemidanaan kelompok hakim berkepribadian otoritarian rendah $(42,57$ bulan). Ada perbedaan pemidanaan antara kelompok hakim berkepribadian otoritarian rendah dengan kelompok hakim berkepribadian otoritarian tinggi. Rerata pemidanaan hakim kelompok berkepribadian otoritarian tinggi $(86,39$ bulan) lebih tinggi dibanding rerata pemidanaan kelompok hakim berkepribadian otoritarian rendah $(42,57$ bulan). Ada perbedaan pemidanaan antara kelompok hakim berkepribadian otoritarian tinggi dengan kelompok hakim berkepribadian otoritarian sedang. Rerata pemidanaan hakim kelompok berkepribadian otoritarian sedang $(61,56$ bulan) lebih rendah dibanding rerata pemidanaan kelompok hakim berkepribadian otoritarian tinggi $(86,39$ bulan).

\section{DAFTAR PUSTAKA}

Altemeyer, B, 1996. The Authoritarian Specter. Cambriedge, Massachusetts: Harvard University Press. 
Baron, R.A., and Byrne, D. 1991. Social Psychology- Understanding Human Interaction. Singapore: Allyn and Bacon.

Billing, S.W.,Guastello,S.J., and Rieke, M.L., 1993. A Comparative Assesment of The Construct Validity of Three Authoritarianism Measure. Journal of Research in Personality, 27, 328348.

Brigham, J.C., 1991. Social Psychology. New York: Harper and Collins.

Dane, F.C., and Wrightsman, L.S. 1982. Effect of Defendant's and victim's Characteristic on Juror's Verdicts. Boston: Houghton Mifflin Company

Feather, N.T. 1996. Reaction of Penalties for an Offense in Relation to Authoritarianism, Values, Perceived Responsibility, Perceived Seriousness and Deservingness. Journal of Personality and Social Psychology, $71,571-587$.

Gerbasi,K.C., Zuckerman, M.s and Reis, H.T. 1977. Justice Needs a New Blinfoid: A Review of Mock Jury Research. Psychological Bulletin, 84,323345 .

Jones, E.E, and Goethals, G.R. 1976. Order and effect in Impression Formation: Attribution Context and The Nature of The Entity. Morriston, New Jersey: General Learning Press.

Karnasudirdja, E.D. 1983. Beberapa pedoman Pemidanaan dan
Pengamatan Pidana. Jakarta: Mahkamah Agung Republik Indonesia.

Moeljatno. 1982. Azas-azas Hukum Pidana. Yogyakarta: Universitas Gadjah Mada.

Muladi dan Nawawi, B. 1992. Teori-teori dan Kebijakan Pldana. Bandung: PenerbitAlumni.

Poernomo, B. 1994. Proses Pengambilan Keputusan Dalam Perkara Pidana di Pengadilan. Makalah (tidak diterbitkan). Disampaikan dalam rangka kuliah Seminar Psikologi Sosial Semester I 1994/1995. Program Pasca Sarjana UGM. Minat Utama Psikologi Sosial.

Rahayu, YP. 1995. Putusan Hakim dalam Perkara Pidana Suatu Kajian Psikologis. Buletin Psikologi Universitas Gadjah Mada Yogyakarta, 3(1), 1-10.

Rickman, R.M., Burns,M.J, and Robbins, M.A. 1986. Authoritarianism and Sentencing strategies for Low and High Severity Crimes. Personality and Social Psychology Bulletin, 12, 227-235.

Sabini,J., 1992. Social Psychology. New York: W.W. Norton Company.

Zebrowitz, L.A. and McDonald, S.M. 1991. The Impact of Litigans' Babyfacedness and Altractiveness of Adjudications in Small Claims Court. Law and Human Behaviour, $15,603-624$. 